\title{
Penerapan Video Animasi Motion Graphic Tentang Pembuatan Kartu Identitas Anak di Kecamatan Sukarami
}

\author{
Hairun Anisyah, Herlambang Saputra, Mustaziri \\ Program Studi Teknologi Informatika Multimedia Digital \\ Politeknik Negeri Sriwijaya \\ hairun.anisa51@gmail.com, herlambang@polsri.ac.id, mustaziri@polsri.ac.id
}

Diterima: 12 Oktober 2019. Disetujui: 23 Oktober 2019. Dipublikasikan : November 2019

\begin{abstract}
Abstrak - Penerapan video animasi motion graphic tentang membuat Kartu Identitas Anak di Kecamatan Sukarami dirancang dan di terapan guna memenuhi keperluan sosialisasi kepada masyarakat terutama orang tua yang memiliki anak di bawah 17 tahun. Dalam video animasi motion graphic ini, menggunakan metode penelitian pengembangan multimedia yaitu Villamil-Molina dan Skala Likert guna menghitung kuesioner yang diberikan saat sosialisasi video. Perhitungan kuesioner memiliki dua kategori, yaitu kuesioner Alfa untuk para ahli di bidang multimedia dengan index presentase rata-rata 71,6 persen, dan video ini berada di kategori video motion graphic yang baik dan kuesioner Beta untuk masyarakat yang membutuhkan infomasi mendapatkan index persentase rata-rata 85,37 persen, dan video ini berada di kategori video dengan informasi yang sangat baik. Video animasi motion graphic dipublikasikan melalui sosialisasi langsung dan media sosial Youtube, sehingga masyarakat dapat menontonnya dimanapun dan kapan pun.
\end{abstract}

Kata Kunci: animasi; kartu identitas anak; media sosialisasi; motion graphic

\section{PENDAHULUAN}

Pemanfaatan komputer sebagai sarana multimedia tidak dapat dipisahkan. Komputer digunakan untuk mencari, membuat, dan menggabungkan data sehingga menciptakan karya yang dapat digunakan orang lain yang memiliki nilai kreatif [1]. Kreativitas dan majunya teknologi membuat perkembangan multimedia sangat meningkat. Hal ini dibuktikan dengan semakin maraknya industri ekonomi kreatif di Indonesia terutama bidang multimedia. Sub-sektor di bidang multimedia yang berkembang pesat adalah animasi [2]. Animasi merupakan salah satu sub-sektor industri ekonomi kreatif prioritas yang dikelola karena sebagai penghela sektor ekonomi kreatif. Bahkan Kementerian Perindustrian mengadakan pendidikan dan pelatihan three in one di Balai Diklat Industri Denpasar guna memberikan pelatihan khusus bidang animasi untuk seluruh masyarakat Indonesia. Pembuatan animasi tidak bisa asal-asalan, dibutuhkan pengumpulan data dan analisis sebelum melakukan produksi. Penentuan jenis animasi, teknik penyampaian pesan, aset-aset yang dibutuhkan, sistem produksi, dan tindak lanjut sosialisasi hasil pembuatan animasi harus dikonsep agar tujuan pembuatan animasi dapat tersampaikan [3].

Berlandaskan pada hal tersebut, dengan permasalahan terkait media sosialisasi tentang Kartu Identitas Anak (KIA) [4] di Kecamatan Sukarami yang bertujuan memberikan informasi terkait proses pembuatan KIA kepada masyarakat terutama orang tua yang memiliki anak di bawah 17 tahun. Selama ini, sosialisasi yang telah dilakukan Kecamatan Sukarami ialah dengan memberikan surat edaran, brosur, dan spanduk kepada Kelurahan yang diteruskan kepada ketua Rukun Tetangga atau RT yang tentunya tidak mendetail membahas proses pembuatan KIA. Sebagaimana data yang terakhir masuk di Kecamatan Sukarami pada Maret tahun 2019 didapatkan 1.306 anak yang telah membuat KIA dari 62.138 data anak yang masuk di wilayah Kecamatan Sukarami. Angka ini sangat minim dibandingkan target anak yang seharusnya sudah membuat KIA. Pembuatan animasi dalam bentuk motion graphic ini menjadi media sosialisasi alternatif baru pembuatan KIA yang tentunya lebih profesional dan menarik dengan berbagai warna dan ikon sehingga dapat mengurangi kebosanan. Karena animasi ini dikemas dalam bentuk video, maka sangat fleksibel jika diintegrasikan dengan media sosial seperti youtube, whatsapp dan sosialisasi langsung. 


\section{TINJAUAN PUSTAKA}

\section{A. Animasi dan Motion Graphic}

Animasi merupakan kumpulan gambar yang ditampilkan secara bergantian dan berurutan sehingga terlihat bergerak dan hidup. Pergerakan animasi lebih mudah dimengerti daripada objek atau gambar diam. Selain itu animasi lebih menarik dan mudah dimengerti daripada hanya sekedar gambar karena lebih komunikatif dalam menyampaikan suatu tujuan. Sedangkan dalam kamus bahasa Indonesia-Inggris, kata animasi berasal dari kata dasar; "to animate", yang berarti menghidupkan. Secara umum animasi merupakan salah satu kegiatan menjalankan atau menggerakkan benda mati, dengan memberikan dorongan, kekuatan, gambaran-gambaran, semangat agar seakan-akan hidup [5].

Motion graphic merupakan salah satu cabang ilmu desain grafis, di mana dalam motion, elemen elemen desain seperti bentuk, raut, ukuran, arah, tekstur yang terdapat di dalamnya, dengan secara sengaja digerakkan atau diberi pergerakan agar tampak hidup [6]. Biasanya motion graphic terdiri dari dua kata, motion yang berarti gerak dan graphic atau yang sering dikenal dengan istilah grafis. Dari asal muasal pengertian dua kata tersebut, motion graphic juga dapat disebut dengan istilah grafis gerak.

\section{B. Teknologi yang digunakan}

Pada pembuatan video animasi motion graphic memerlukan berbagai alat teknologi dalam menunjang proses produksi. Teknologi yang digunakan dalam bentuk hardware yaitu laptop dengan spesifikasi RAM $8 \mathrm{~GB}$, Intel Core I5, kamera, recording audio, dan pen tablet. Sedangkan software yang digunakan ialah software pengeditan suara, pengeditan video, dan animasi 2D.

Adapun teknik animating pada pembuatan video animasi motion graphic ini menggunakan teknik puppet pin yaitu sebuah tool dari software animasi editing. Menganimasikan karakter pada puppet pin menggunakan beberapa titik-titik untuk menggerakkan struktur dari kerangka karakter.

\section{Kerangka Penelitian}

Kerangka penelitian meliputi tahapan yang dilakukan selama melakukan penelitian. Penelitian yang dikembangkan dilakukan pada tahapan berikut:

- Studi literatur Mengenai Pembuatan video animasi sosialisasi dalam bentuk Motion Graphic, dan KIA di Kecamatan Sukarami.

- Mengumpulkan data video yang dapat digunakan untuk pengujian.
- Membuat video animasi sosialisasi mengenai proses pembuatan KIA.

- Melakukan pengujian terhadap video animasi yang telah dibuat dengan melakukan sosialisasi kepada Ibu-Ibu PKK dan Posyandu.

- Melakukan analisis terhadap hasil pengujian video animasi yang telah disosialisasi.

- Membuat kesimpulan dari hasil analisis dan pembahasan.

Proses perancangan video animasi ini dijelaskan pada Gambar 1.

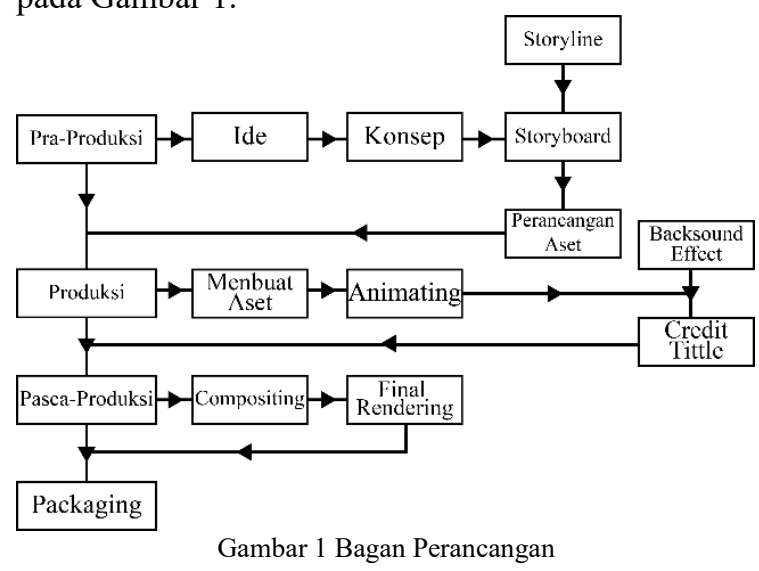

\section{Metode Villamil-Molina}

Pada tahapan ini perancangan video animasi sosialisasi menggunakan metode pengembangan Villamil-Molina [7]. Metode ini mengatakan bahwa pengembangan multimedia akan berhasil baik dengan membutuhkan perencanaan yang teliti, penguasaan teknologi multimedia yang baik, serta penguasaan manajemen produksi yang baik juga. Dengan kata lain, keberhasilan pengembangan multimedia merupakan hasil dari pekerjaan tim yang terpadu. Metode ini memiliki beberapa tahapan kegiatan seperti Development, Pre-Production, Production, Post-Production, dan Delivery.

\section{PERANCANGAN DAN REALISASI}

\section{A. Pra Produksi}

Pada tahap ini peneliti menentukan tujuan dengan membuat ide, konsep, storyline, storyboard, pengumpulan dan pembuatan aset.

- Ide

Awal mula ide dalam pembuatan video animasi Iklan Layanan Masyarakat berkaitan dengan minimnya masyarakat membuat KIA untuk anaknya di Kecamatan Sukarami. Sehingga, terciptalah ide untuk membantu sosialisasi pembuatan Kartu Identitas Anak di masyarakat.

- Konsep

Video ini menjelaskan tentang proses pembuatan KIA, hal ini terlihat dengan menampilkan informasi penting mengenai syarat dan prosedur pembuatan KIA. Informasi 
tersebut berdasarkan informasi yang telah didapat dan dapat dipertanggung jawabkan.

- Storyline

Berikut ini merupakan babak dari beberapa bagian scene dari storyline video ini:

\section{Storyline Video Animasi Iklan Layanan Masyarakat yang berjudul "Membuat Kartu Identitas Anak di Kecamatan Sukarami".}

\section{- BABAK 1 (INTRO)}

Menampilkan judul dan typografi penjelasan Karti Identitas Anak.

- BABAK 2 (FUNGSI DAN MANFAAT)

Menampilkan ilustrasi dari fungsi dan manfaat Kartu Identitas Anak

- BABAK 3 (PROSEDUR)

- Menampilkan ilustrasi dari prosedur pembuatan Kartu Identitas Anak.

- Storyboard

Di tahap ini peneliti menggunakan storyboard untuk menggambarkan deskripsi tiap scene. Storyboard Membuat Kartu Identitas Anak

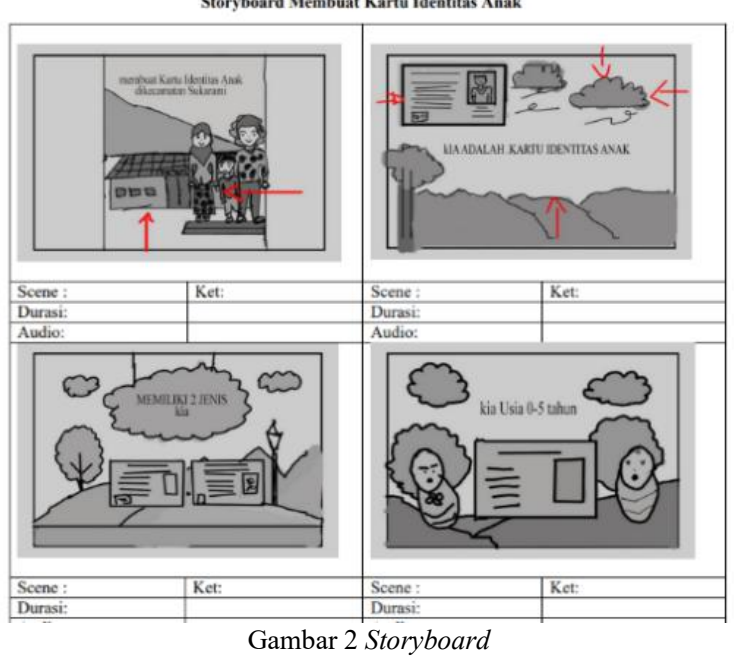

- Pengumpulan dan Merancang Aset

Pada tahap ini pengumpulan bahan berupa asetaset animasi, font, sound effect dan musik. Untuk pengumpulan video dilakukan dengan melakukan proses pembuatan file grafis.

\section{B. Produksi}

Pada tahap produksi terdapat beberapa proses yang harus ditempuh, yaitu membuat aset, animating, compositing dan pemberian efek. Pembuatan video animasi berdasarkan outline atau storyboard dan proses kreatif yang berasal dari tahap desain konsep.

- Pembuatan aset, dalam tahap ini penulis membuat aset yang terdiri dari tiga babak.

- Animating, pada tahap ini penulis menganimasikan aset yang telah dibuat.
- Backsound Effect dalam pembuatan video animasi ini sangat berfungsi dikarenakan menambah menariknya video dan tidak membosankan dalam menonton video animasi tersebut.

- Credit Title ditampikan akhir dalam video animasi agar terlihat lebih menarik. Contohnya pengucapan syukur dan terima kasih terhadap orang-orang yang terlibat dalam pembuatan video animasi, dan sebagai identitas dari pembuat video tersebut.

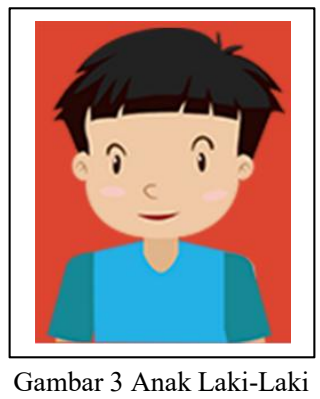

\section{Pasca Produksi}

Pada tahap pasca produksi terdapat beberapa proses yang harus ditempuh, yaitu membuat Compositing dan Video Editing, Final Rendering atau Rendering Compositing.

- Compositing dan Video Editing, tahap ini merupakan proses penggabungan dan cutting video-video animasi yang sebelumnya.

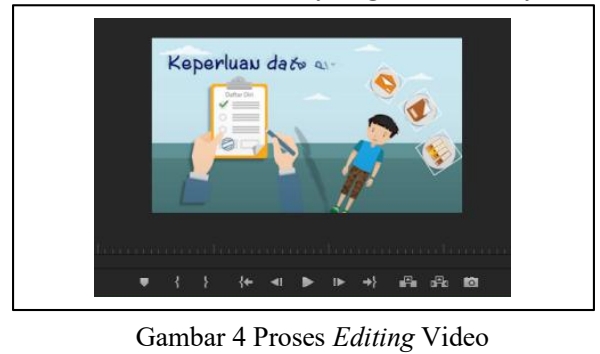

- Final Rendering, tahap ini dilakukan penggabungan dari keseluruhan proses yang telah dikerjakan. Dari proses rendering ini akan dihasilkan video dengan format file *.mp4.

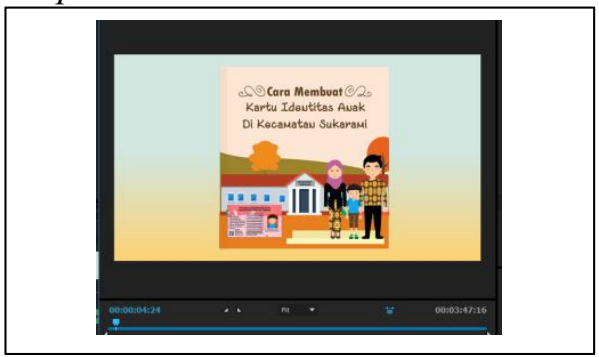

Gambar 5 Melakukan Final Rendering

\section{Perancangan Kuesioner}

Kuesioner [8] disusun untuk mengumpulkan biodata responden Alfa sebagai ahli di bidang 
multimedia dan responden Beta sebagai sasaran informasi disampaikan, data dalam segi konten informasi dan data dalam segi tampilan. Data yang diambil dalam biodata responden online adalah nama, umur, email, jenis kelamin, dan tingkat pendidikan. Sedangkan data yang diambil dalam biodata responden offline adalah nama, umur, usia, jenis kelamin, dan tingkat pendidikan. Data-data lain lebih lengkapnya dijelaskan pada Tabel I dan II.

TABEL I. PERTANYAAN DALAM PENGUJIAN ALFA DALAM SEGI TAMPILAN

\begin{tabular}{|c|l|c|c|c|c|c|}
\hline \multirow{2}{*}{ No } & \multicolumn{1}{|c|}{ Pertanyaan } & \multicolumn{5}{|c|}{ Pilihan Jawaban } \\
\cline { 3 - 7 } 1 & $\mathbf{1}$ & $\mathbf{2}$ & $\mathbf{3}$ & $\mathbf{4}$ & $\mathbf{5}$ \\
\hline & $\begin{array}{l}\text { Apakah iklan ini } \\
\text { menarik dari segi } \\
\text { gambar/grafis? }\end{array}$ & & & & & \\
\hline 2 & $\begin{array}{l}\text { Apakah iklan ini } \\
\text { menarik dari } \\
\text { segi warna? }\end{array}$ & & & & & \\
\hline 3 & $\begin{array}{l}\text { Apakah iklan ini } \\
\text { menarik dari segi } \\
\text { tipografi (teks)? }\end{array}$ & & & & & \\
\hline 4 & $\begin{array}{l}\text { Apakah iklan ini } \\
\text { menarik dari segi } \\
\text { animasi? }\end{array}$ & & & & & \\
\hline 5 & $\begin{array}{l}\text { Apakah iklan ini } \\
\text { menarik dari } \\
\text { segi audio? }\end{array}$ & & & & & \\
\hline
\end{tabular}

TABEL II. PERTANYAAN PENGUJIAN BETA DALAM SEGI KONTEN INFORMASI

\begin{tabular}{|c|c|c|c|c|c|c|}
\hline \multirow{2}{*}{ No } & \multirow{2}{*}{ Pertanyaan } & \multicolumn{5}{|c|}{ Pilihan Jawaban } \\
\hline & & 1 & 2 & 3 & 4 & 5 \\
\hline 1 & $\begin{array}{l}\text { Apakah informasi } \\
\text { dari iklan ini } \\
\text { mudah dimengerti? }\end{array}$ & & & & & \\
\hline 2 & $\begin{array}{l}\text { Apakah isi informasi } \\
\text { yang diberikan sudah } \\
\text { lengkap? }\end{array}$ & & & & & \\
\hline 3 & $\begin{array}{l}\text { Apakah penyampaian } \\
\text { informasi dengan } \\
\text { animasi Motion } \\
\text { Graphic seperti ini } \\
\text { mudah Anda pahami? }\end{array}$ & & & & & \\
\hline 4 & $\begin{array}{l}\text { Apakah video } \\
\text { sosialisasi ini mampu } \\
\text { mengajak masyarakat } \\
\text { untuk membuat Kartu } \\
\text { Indentitas Anak? }\end{array}$ & & & & & \\
\hline
\end{tabular}

Keterangan:

5: Sangat Baik, 4: Baik, 3: Cukup, 2: Kurang, 1: Sangat Kurang

\section{E. Objek Penelitian}

Agar video yang disosialisasikan dapat tepat memenuhi kebutuhan masyarakat mengenai informasi proses pembuatan kartu identitas anak, maka dipilih objek penelitian yang merupakan target dari penyampaian video. Adapun objek penelitian yang dipilih adalah:

- $\quad$ Orang Tua yang memiliki anak dibawah 17 tahun.

- Masyarakat yang membutuhkan informasi seperti Posyandu dan ibu-ibu PKK yang ada di sekitar Kecamatan Sukarami.

\section{F. Tes Kinerja Sistem}

Adapun tolak ukur keberhasilan dalam penelitian ini, dapat dilihat melalui kuesioner yang akan dibagikan dalam sosialisasi online dan offline. Kuesioner akan dibagikan kepada Komunitas Orang Tua seperti ibu-ibu PKK dan Posyandu sebanyak 15 koresponden. Sedangkan secara online melalui membagi link video dan kuesioner online yang terbuat di google document sebanyak 25 koresponden. Kuesioner yang terbuat dari google document akan diberikan kepada 10 ahli.

\section{G. Analisis Kuesioner}

Untuk dapat menyimpulkan data yang diperoleh dari hasil kuesioner yang telah diisi diperlukan perhitungan dengan rumus tertentu agar didapatkan persentase dari setiap jawaban dari responden. Penulis menggunakan persamaan persentase sebagai acuannya. Di bawah ini merupakan rancangan perhitungan yang akan digunakan skala Likert.

\section{H. Perhitungan Skala Likert}

Skala Likert [9] merupakan metode skala bipolar yang mengukur baik tanggapan positif ataupun negatif terhadap suatu pernyataan. Dalam membuat skala Likert, ada beberapa langkah prosedur yang harus dilakukan, antara lain:

- Peneliti mengumpulkan item-item yang cukup banyak, memiliki relevansi dengan masalah yang sedang diteliti, dan terdiri dari item yang cukup jelas disukai dan tidak disukai.

- Item-item diuji cobakan pada sekelompok responden yang cukup representatif dari populasi yang ingin diteliti.

- Responden di atas diminta untuk mengecek tiap item, apakah ia menyenangi $(+)$ atau tidak menyukainya (-). Respon tersebut dikumpulkan dan jawaban yang memberikan indikasi menyenangi diberi skor tertinggi. Tidak ada masalah untuk memberikan angka 5 untuk yang tertinggi dan skor 1 untuk yang terendah atau sebaliknya. Adapun yang penting adalah konsistensi dari arah sikap yang diperlihatkan. Demikian juga apakah jawaban "setuju" atau 
"tidak setuju" disebut yang disenangi, tergantung dari isi pertanyaan dan isi dari itemitem yang disusun.

- Total skor dari masing-masing individu adalah penjumlahan dari skor masing-masing item dari individu tersebut. Respon dianalisis untuk mengetahui item-item mana yang sangat nyata batasan antara skor tinggi dan skor rendah dalam skala total.

Adapun langkah untuk mencari jawaban responden adalah dengan menggunakan persamaan (1)

- Adapun langkah pertama persamaan dari skala Likert adalah sebagai berikut.

$$
\mathrm{J}_{\mathrm{R}}=T \times P n
$$

Keterangan:

$\mathrm{J}_{\mathrm{R}}=$ Jawaban Responden

$\mathrm{T}=$ Total jumlah responden yang memilih

$\mathrm{Pn}=$ Pilihan angka skor Likert

- Pada langkah kedua untuk mendapatkan hasil interpretasi, tentukan skor tertinggi (X) dan skor terendah (Y) untuk item penilaian dengan rumus sebagai berikut:

$X=$ skor tertinggi $x$ jmh responden
$Y=$ skor terendah $x$ jmh responden

- Pada langkah ketiga setelah mendapatkan skor tertinggi dan terendah, tentukan nilai dari persentase total skor yaitu dengan rumus sebagai berikut :

$\mathrm{R}_{\mathrm{I}}=\frac{\text { Total skor }}{\mathrm{Y}} 100 \%$

Keterangan:

R $=$ Rumus Index \%

- Pada langkah keempat tentukan interval (rentang jarak) dan interpretasi persen untuk mengetahui penilaian yaitu sebagai berikut :

$\mathrm{I}=\frac{100 \%}{\text { Jumlah Skor Likert }}$

Keterangan:

$\mathrm{I}=$ Interval

Hasil intervalnya jarak dari terendah $0 \%$ hingga tertinggi $100 \%$, berikut kriteria interpretasi skornya berdasarkan interval:

Angka $0 \%-19,99 \%=$ Sangat kurang

Angka 20\% - 39,99\% = Kurang

Angka 40\% - 59,99\% = Cukup / Netral

Angka 60\% - 79,99\% = Baik

Angka 80\% - 100\% = Sangat Baik

\section{PEMBAHASAN}

\section{A. Pengujian}

Setelah menghasilkan video yang telah dibuat, selanjutnya peneliti melakukan pengujian (testing). Pengujian dibagi menjadi dua, yaitu pengujian Alfa dan pengujian Beta dari hasil video animasi yang telah disosialisasikan kepada beberapa responden dengan menyebarkan kuesioner.

\section{B. Pengujian Alfa}

Bertujuan untuk meninjau apakah animasi yang telah dibuat berjalan dengan baik. Dalam pengujian dilakukan oleh para ahli animasi dengan melihat hasil akhir video yang telah di-render sebelumnya sehingga dapat dinilai dari segi penampilan animasi seperti berikut:

- Segi Gambar / Grafis

- Segi Warna

- Segi Typografi / tulisan

- Segi Animasi / gerakan

- Segi Audio

\section{Pengujian Beta}

Dari pengujian Beta bertujuan untuk meninjau apakah animasi yang telah dibuat dapat memberikan memahaman informasi kepada masyarakat tentang manfaat dan cara membuat Kartu Identitas Anak di Kecamatan Sukarami. Dalam pengujian dilakukan oleh para ibu-ibu posyandu secara langsung dan masyarakat umum yang memiliki anak di bawah usia 17 tahun, dengan melihat hasil akhir video yang telah di-render sebelumnya, sehingga dapat dinilai dari segi informasi yang didapatkan.

\section{Data Hasil Pengujian}

Peneliti merekap data yang masuk dan memasukan data ke dalam tabel untuk bisa dianalisis dengan baik. Setelah melakukan pengujian, maka diperoleh data hasil pengujian pada Tabel III dan IV.

- Data hasil pengujian Alfa dilakukan untuk mengetahui kelayakan video animasi sosialisasi yang dibuat. Penilaian kelayakan video dilakukan oleh ahli di bidang animasi khususnya dan multimedia pada umumnya, dengan melihat dari jurusan pendidikan dan pekerjaannya di bidang animasi ataupun multimedia.

TABEL III. PERTANYAAN PENGUJIAN ALFA

\begin{tabular}{|c|l|c|c|c|c|c|}
\hline \multirow{2}{*}{ No } & \multirow{2}{*}{ Pertanyaan } & \multicolumn{5}{|c|}{ Pilihan Jawaban } \\
\cline { 2 - 7 } 1 & 1 & 2 & 3 & 4 & 5 \\
\hline 2 & $\begin{array}{l}\text { Apakah iklan ini } \\
\text { menarik dari segi } \\
\text { gambar/grafis? }\end{array}$ & - & - & 4 & 6 & - \\
\hline & $\begin{array}{l}\text { Apakah iklan ini } \\
\text { menarik dari segi } \\
\text { warna? }\end{array}$ & - & - & 2 & 8 & - \\
\hline 3 & $\begin{array}{l}\text { Apakah iklan ini } \\
\text { menarik dari segi } \\
\text { tipografi (teks)? }\end{array}$ & - & 2 & 3 & 5 & - \\
\hline 4 & $\begin{array}{l}\text { Apakah iklan ini } \\
\text { menarik dari segi } \\
\text { animasi? }\end{array}$ & - & 1 & 3 & 6 & - \\
\hline
\end{tabular}




\begin{tabular}{|l|l|l|l|l|l|l|}
\hline 5 & $\begin{array}{l}\text { Apakah iklan ini } \\
\text { menarik dari segi } \\
\text { audio? }\end{array}$ & - & - & 3 & 7 & - \\
\hline
\end{tabular}

- Responden terdiri dari 15 ibu posyandu dan 25 masyarakat umum yang memiliki anak atau pun saudara berusia kurang dari 17 tahun. Tujuan video sosialisasi adalah dapat memberikan informasi dengan jelas terkait membuat KIA di Kecamatan Sukarami.

TABLE IV. PERTANYAAN PENGUJIAN BETA

\begin{tabular}{|c|l|c|c|c|c|c|}
\hline \multirow{2}{*}{ No } & \multicolumn{1}{|c|}{ Pertanyaan } & \multicolumn{5}{|c|}{ Pilihan Jawaban } \\
\cline { 2 - 6 } & & 1 & 2 & 3 & 4 & 5 \\
\hline 1 & $\begin{array}{l}\text { Apakah informasi } \\
\text { dari iklan ini } \\
\text { mudah } \\
\text { dimengerti? }\end{array}$ & - & & 3 & 16 & 21 \\
\hline 2 & $\begin{array}{l}\text { Apakah isi } \\
\text { informasi yang } \\
\text { diberikan sudah } \\
\text { lengkap? }\end{array}$ & - & 3 & 6 & 17 & 14 \\
\hline 3 & $\begin{array}{l}\text { Apakah } \\
\text { penyampaian } \\
\text { informasi dengan } \\
\text { animasi Motion } \\
\text { Graphic seperti ini } \\
\text { mudah Anda } \\
\text { pahami? }\end{array}$ & - & - & 4 & 14 & 22 \\
\hline & $\begin{array}{l}\text { Apakah video } \\
\text { sosialisasi ini } \\
\text { mampu mengajak } \\
\text { masyarakat untuk } \\
\text { membuat Kartu } \\
\text { Indentitas Anak? }\end{array}$ & - & 3 & 4 & 16 & 17 \\
\hline
\end{tabular}

E. Analisis

Analisis data dalam pengujian Alfa, dihitung berdasarkan masing-masing poin di setiap pertanyaannya dengan menggunakan skala Likert. Ada 10 responden atau ahli yang memberikan jawaban dari kuesioner yang diberikan. Ada pun perhitungannya pada Gambar 6 .

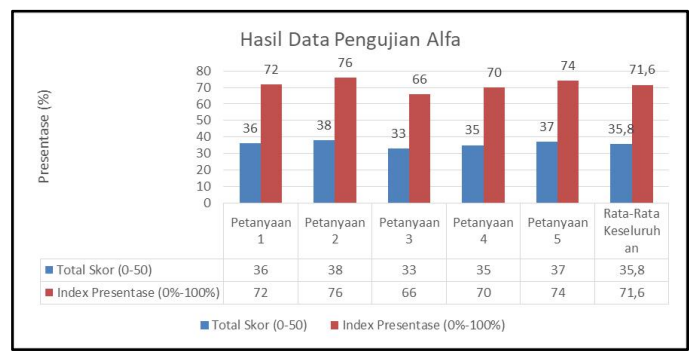

Gambar 6 Tampilan Diagram Hasil Data Alfa

Sama seperti halnya pengujian Alfa, dalam pengujian Beta dibutuhkan perhitungan berdasarkan poin pada setiap pertanyaan yang dijawab. Pengujian
Beta memiliki 40 responden yang telah menjawab empat pertanyaan kuesioner yang diberikan. Adapun perhitungannya pada Gambar 7.

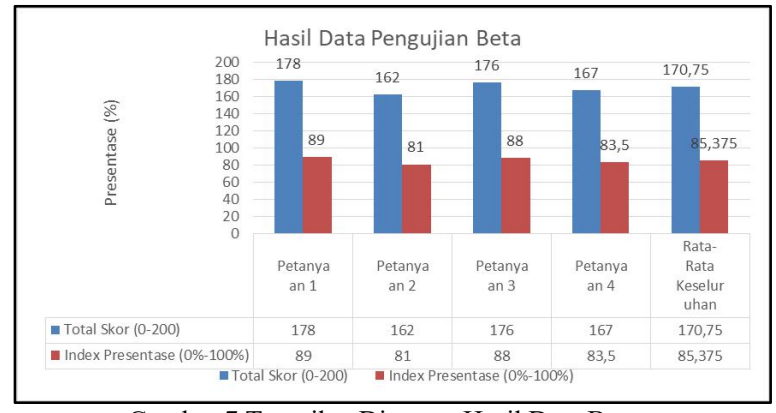

Gambar 7 Tampilan Diagram Hasil Data Beta

\section{KESIMPULAN}

Berdasarkan hasil dari pembahasan terkait penerapan motion graphic sebagai media sosialisasi tentang proses pembuatan Kartu Identitas Anak, dalam penelitian dan perancangan pembuatan video sosialisasi dalam bentuk motion graphic tentang membuat Kartu Identitas Anak yang telah dikerjakan, maka dapat diambil beberapa kesimpulan yaitu:

- Pembuatan video sosialisasi tentang membuat Kartu Identitas Anak ini menggunakan animasi dengan pendekatan motion graphic yang menarik, menghasilkan video berdurasi 2 menit 45 detik dengan format *.mp4. Sehingga informasi yang diberikan mempermudah untuk dicerna masyarakat.

- Responden alfa, dilihat dari latar belakang usia, jenis kelamin, pekerjaan, tingkat pendidikan, dan jurusan pendidikan. Sehingga berkompeten dalam menilai video yang telah di buat. Sedangkan responden beta, dilihat dari latar belakang jenis kelamin, usia, tingkat pendidikan, dan usia anak. Memiliki kategori yang membutuhkan informasi dari video.

- Video motion graphic tentang sosialisasi membuat Kartu Identitas Anak dari segi grafik atau gambar, warna, typografi (teks), animasi, dan audio mendapatkan index presentasi rata-rata $71,6 \%$, dan video ini berada di kategori video motion graphic yang baik.

- Video motion graphic memberikan informasi yang mudah di mengerti, lengkap, pendekatan dengan motion graphic yang mudah di pahami, serta mampu mengajak masyarakat untuk sadar akan kebutuhan membuat Kartu Identitas Anak. Sehingga mendapatkan index presentasi rata-rata 
$85,37 \%$. Video ini berada di kategori video dengan informasi yang sangat baik.

\section{REFERENS}

[1] Hadi Wijaya, "Profil Jurusan Teknik Komputer Politeknik Negeri Sriwijaya Dengan Metode Expository Documentary Film Sebagai Sarana Promosi \& Media Informatif” Skripsi, Jurusan Teknik Komputer, Teknologi Informatika Multimedia Digital, Politeknik Negeri Sriwijaya, 2017.

[2] Yesty Desca Refita Putri, "Pembuatan Motion Graphics Sebagai Media Sosialisasi dan Promosi untuk aplikasi mobile tranding online mandiri sekuritas," Jurnal Ilmiah Manajemen Informatika dan Komputer, Politeknik Negeri Jakarta. Jakarta: Yayasan Kopertip Indonesia, Vol 1(2). Hal 85-92, 2017.

[3] Rudianto, "Perancangan Animasi Multimedia Iklan Layanan Masyarakat tentang proses pembuatan E-KTP," Jurnal Akrab Juara, Universitas AMIK BSI, Jakarta Barat: Yayasan Akrab Pekanbaru. Vol. 3(1). Hal 31-38, 2018.
[4] Chandy Afrizal, "Pelaksanaan Kebijakan Pembuatan Kartu Identitas Anak Di Kota Bandar Lampung," Fakultas Hukum, Hukum Administrasi Negara, Universitas Lampung, 2017.

[5] Arief Ruslan, "Animasi: Perkembangan dan Konsepnya," Bogor, Ghalia Indonesi, 2016

[6] Umam, N. C. "Perancangan Motion Graphic Pengenalan Batik Gemawang Khas Kabupaten Semarang," Fakultas Seni Rupa, Institut Seni Indonesia Yogyakarta, 2016.

[7] Iwan Binato,"Perbandingan Metode Pengembangan Perangkat Lunak Multimedia. Makalah dipresentasikan pada Seminar Nasional Riset dan Teknologi Terapan," September 26-27, Jakarta. 2013

[8] Rovianto, Adi Rahman. "Pengembangan Iklan Layanan Masyarakat Dengan Pendekatan Infografis Tentang Pentingnya Konsumsi Air Putih.” Skripsi. Program Studi Teknik Informatika, Jurusan Teknik Informatika Dan Komputer, Politeknik Negeri Jakarta, 2015.

[9] Ratih Suryani, Herlambang Saputra, Adi Sutrisman, "Implementasi Animasi 2d pada Iklan Layanan Masyarakat sebagai Sosialisasi Penyakit DBD," Politeknik Negeri Sriwijaya, Jurnal Rekam, Vol. 15 No. 2, 2019. 